\title{
Erratum
}

\section{Investigation of metal cluster layers by EELS}

Hellmut Seiler, Ulrich Haas, Karl-Heinz Körtje and Bernd Ocker

(Microsc. Microanal. Microstruct. 2 (1991) 191-201)

The correct figure 1 is:

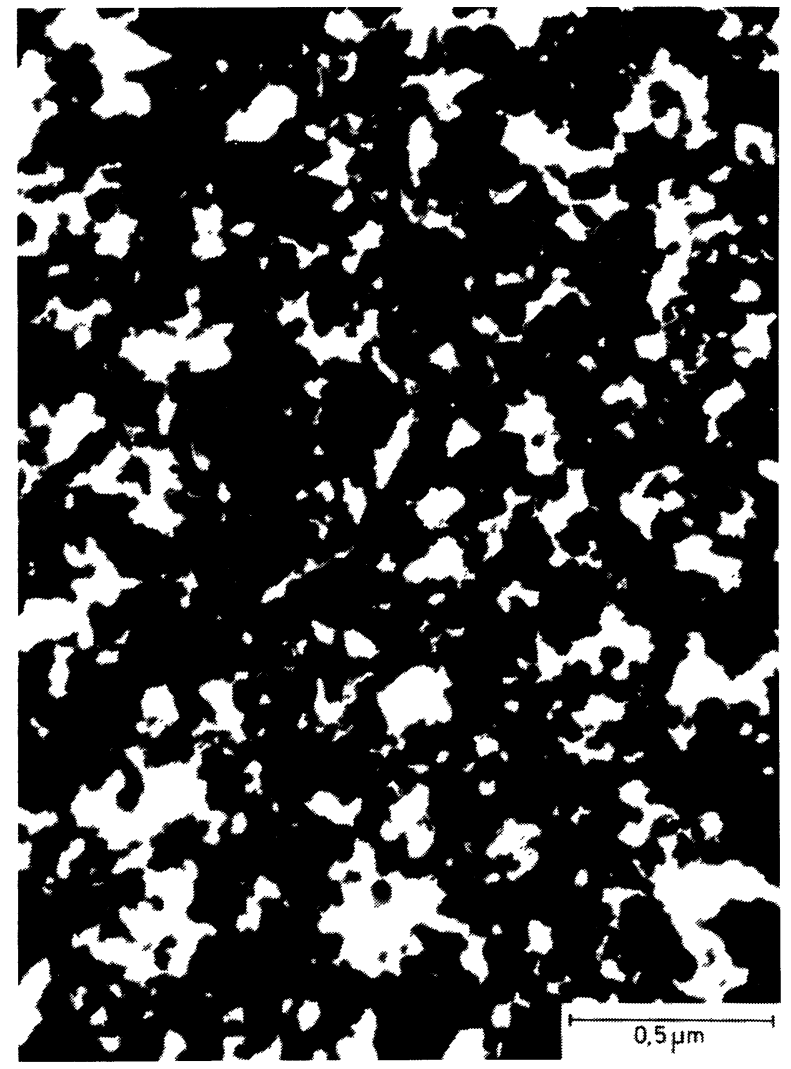

Commission paritaire $\mathrm{N}^{\circ}$ en cours 